\title{
manejo de Plantas daninhas na Cultura do Algodoeiro em Sistema de Plantio Direto ${ }^{1}$
}

\author{
Weed Management of Cotton Under No-Tillage
}

FREITAS, R.S. ${ }^{2}$, BERGER, P.G. ${ }^{3}$, FERREIRA, L.R. ${ }^{3}$, SILVA, A.C. ${ }^{4}$, CECON, P.R. ${ }^{5}$ e SILVA, M.P. ${ }^{6}$

\begin{abstract}
RESUMO - Este trabalho foi realizado com objetivo de avaliar a eficiência dos herbicidas s-metolachlor, em pré-emergência, e trifloxysulfuron-sodium, aplicado aos 18 dias após a emergência do algodão (DAE), em sistema de plantio direto. Foi utilizado o arranjo fatorial $(4 \times 4)+1$, sob delineamento de blocos casualizados, com quatro repetições. O primeiro fator constituiu-se de quatro doses de S-metolachlor $\left(0,384,768\right.$ e $\left.1.152 \mathrm{~g} \mathrm{ha}^{-1}\right)$ e o segundo de quatro doses de trifloxysulfuron-sodium $\left(0,0 ; 2,625 ; 5,250 ;\right.$ e 7,875 $\left.\mathrm{g} \mathrm{ha}^{-1}\right)$, mais uma testemunha mantida no limpo por todo o ciclo do algodoeiro. As plantas daninhas foram avaliadas aos 25, 45 e 60 DAE. Na área, foi verificada a presença das seguintes espécies daninhas: Alternanthera tenella (apaga-fogo), representando mais de 80\% do total, Tridax procumbens (erva-de-touro), Bidens sp. (picão-preto), Acanthospermum hispidum (carrapicho-de-carneiro), Cenchrus echinatus (capim-carrapicho), Digitaria horizontalis (capim-colchão), Eleusine indica (capim-pé-de-galinha) e Commelina benghalensis (trapoeraba). O S-metolachlor apresentou baixa eficiência de controle destas espécies, no entanto o trifloxysulfuron-sodium teve seu desempenho melhorado quando foi aplicado S-metolachlor. O melhor controle foi obtido com a combinação de S-metolachlor a $1.152 \mathrm{~g} \mathrm{ha}^{-1}$ com trifloxysulfuron-sodium a 7,875 $\mathrm{g} \mathrm{ha}^{-1}$, que apresentou controle superior a $90 \%$ de A. tenella e do total de plantas daninhas até 60 DAE. Todavia, esse controle não foi suficiente para permitir a colheita do algodão no limpo. As combinações de S-metolachlor a 384 e $768 \mathrm{~g} \mathrm{ha}^{-1}$ com trifloxysulfuron-sodium a 7,875 $\mathrm{g} \mathrm{ha}^{-1}$ e de S-metolachlor a $1.152 \mathrm{~g} \mathrm{ha}^{-1} \mathrm{com}$ trifloxysulfuron-sodium nas doses de 5,250 e 7,875 $\mathrm{g} \mathrm{ha}^{-1}$ proporcionaram rendimentos semelhantes aos da testemunha capinada.
\end{abstract}

Palavras-chave: S-metolaclhor, triflosysulfuron-sodium, Gossypium hirsutum, seletividade.

\begin{abstract}
The objective of this study was to evaluate the efficiency of the herbicides S-metolachlor in pre-emergence and trifloxysulfuron-sodium applied 18 days after crop emergence (DAE), under no-tillage systems. A factorial scheme $(4 x 4)+1$ was used in a completely randomized block design, with four replications. The first factor consisted of four S-metolachlor doses $(0,384$, 768 and $\left.1.152 \mathrm{~g} \mathrm{ha}^{-1}\right)$ and the second of four trifloxysulfuron-sodium doses (0.0; 2.625; 5.250; and $7.875 \mathrm{~g} \mathrm{ha}^{-1}$ ), plus a control kept weeded throughout the cotton cycle. The weeds were evaluated 25, 45 and 60 DAE. The following weed species were present in the area: Alternanthera tenella, representing over 80\% of the total, Bidens spp., Tridax procumbens, Acanthospermum hispidum, Ipomoea grandifolia, Digitaria horizontalis, Eleusine indica, and Commelina benghalensis. S-metolachlor controlled these species with low efficiency. The best control was obtained with the combination of S-metolachlor at $1.152 \mathrm{~g} \mathrm{ha}^{-1}$ with trifloxysulfuron-sodium at $7.875 \mathrm{~g} \mathrm{ha}^{-1}$, which controlled more than $90 \%$ of A. tenella and other dicotyledonous weeds until $60 \mathrm{DAE}$. This control was still not sufficient to clear the ground for the cotton harvest. The combinations S-metolachlor at 384 and $768 \mathrm{~g} \mathrm{ha}^{-1}$ with trifloxysufuron-sodium at $7.875 \mathrm{~g} \mathrm{ha}^{-1}$ and S-metolachlor at $1.152 \mathrm{~g} \mathrm{ha}^{-1}$ with trifloxysulfuron-sodium in the doses 5.250 and $7.875 \mathrm{~g} \mathrm{ha}^{-1}$ provided similar yields for the weeded control.
\end{abstract}

Keywords: S-metolachlor, triflosysulfuron-sodium, Gossypium hirsutum, selectivity.

Recebido para publicação em 15.3.2005 e na forma revisada em 5.5.2006.

Pesquisador Científico I/APTA - Pólo Regional do Noroeste Paulista; Floreal Km 4, Caixa Postal 61, 15500-000 VotuporangaSP, <freitas@ aptaregional.sp.gov.br>; ${ }^{3}$ Prof. do Dep. de Fitotecnia, Universidade Federal de Viçosa - DFT/UFV; ${ }^{4}$ Pesquisador Científico I/APTA - Pólo Regional da Alta Sorocabana; ${ }^{5}$ Prof. do Dep. de Informática; ${ }^{6}$ Eng.-Agr. - UEMG/Ituiutaba.

Planta Daninha, Viçosa-MG, v. 24, n. 2, p. 339-346, 2006 


\section{INTRODUÇÃO}

As plantas daninhas constituem um dos principais componentes bióticos do agroecossistema do algodoeiro; uma vez não manejadas adequadamente, elas interferem no crescimento, na produtividade, na qualidade de fibras e no beneficiamento (Laca-Buendia, 1990; Freitas et al., 2002, 2003). Além disso, competem com a cultura pelos recursos do meio, principalmente água, luz e nutrientes, liberando substâncias alelopáticas prejudiciais, atuando como hospedeira de pragas e doenças comuns à cultura e interferindo nas práticas de colheita (Pitelli, 1985). Todavia, a competição entre plantas se estabelece sob condições específicas, quando o ambiente e o solo são capazes de apenas suprir quantidades limitadas dos fatores essenciais para o crescimento normal de uma população de plantas (Nieto et al., 1968; Hewson \& Roberts, 1973). O algodoeiro é, normalmente, cultivado em espaçamento largo $(0,8$ a $1,0 \mathrm{~m})$ e apresenta crescimento inicial lento, o que favorece o crescimento das plantas daninhas, em especial nos primeiros meses, necessitando que estas sejam adequadamente manejadas para não comprometer o potencial produtivo da cultura.

Desse modo, um programa eficiente de manejo de plantas daninhas inclui a combinação de estratégias que evitem a concorrência destas plantas com o algodoeiro pelos fatores de produção durante o período crítico de interferência, que, segundo Salgado et al. (2002), é dos 8 aos 66 dias após a emergência, além de não prejudicarem as operações de colheita e pós-colheita.

No cerrado brasileiro, em especial no Mato Grosso, o algodão vem sendo cultivado em extensas áreas, onde o uso de herbicidas assume lugar de destaque (Beltrão, 2004). Diversas modalidades de aplicação de herbicidas, em relação à cultura e às plantas daninhas, são utilizadas no algodoeiro em sistema de plantio direto: pré-plantio, pré-emergência, pós-emergência total e dirigida (Takizawa, 2000; Beltrão, 2004; Rodrigues \& Almeida, 2005).

Em pré-emergência, diversos herbicidas podem ser usados isoladamente ou em misturas para manejo de plantas daninhas em algodoeiro, entre eles o S-metolachlor (O'Connell et al., 1998). Contudo, quando se utilizam herbicidas em pré-emergência no sistema de plantio direto, estes podem apresentar redução de sua eficiência, sendo a palhada um dos fatores que mais contribuem para isso, por evitar que as moléculas do herbicida atinjam o solo uniformemente (Banks \& Robinson, 1986; Burgos \& Talbert, 1996; Ferri \& Vidal, 2002, 2003).

A aplicação dirigida pode viabilizar o uso de muitas moléculas que são tóxicas para o algodoeiro, embora freqüentemente leve a aplicações que resultam em alta toxidez, menor qualidade de fibra e menor rendimento (Guthrie \& York, 1989; Snipes \& Mueler, 1992; Monks et al., 1999; Foloni et al., 1999). Assim, um herbicida seletivo à cultura, aplicado em área total que apresente controle de importantes espécies daninhas, é de grande valia para a cultura do algodoeiro. Nesse sentido, o trifloxysulfuron-sodium assume singular importância, pois diversos trabalhos têm comprovado sua seletividade e eficácia no controle de algumas espécies de folhas largas no algodoeiro (Holloway Júnior et al., 2000; Hudetz et al., 2000; Troxler et al., 2001; Crooks et al., 2001; Oliveira Júnior et al., 2002; Porterfield et al., 2002). Entretanto, o período de espera para o plantio de culturas sensiveis sucessoras, recomendado pelo fabricante, é de nove meses a contar de sua aplicação, o que pode limitar sua utilização em áreas onde o agricultor cultiva, por exemplo, feijão no inverno ou milho na primavera (Procópio et al., 2004). Dessa forma, a possivel redução na dose aplicada do trifloxysulfuron-sodium pode ser decisiva para o sucesso do manejo de plantas daninhas com este herbicida na cultura do algodoeiro, pois, além de reduzir a probabilidade de afetar as plantas sensíveis em cultivo subseqüente, implica redução nos custos de controle e de impacto ambiental.

Este trabalho foi realizado com o objetivo de avaliar a eficiência do herbicida S-metolachlor, em pré-emergência, combinado com trifloxysulfuron-sodium, em pós-emergência, no manejo de plantas daninhas na cultura do algodoeiro em plantio direto.

\section{MATERIAL E MÉTODOS}

O experimento foi instalado em uma área com 5,8 t ha-1 de palha (anteriormente 
cultivada com milho) pertencente à Central de Experimentação, Pesquisa e Extensão do Triângulo Mineiro - CEPET/UFV, Capinópolis, Minas Gerais (longitude de $49^{\circ} 34^{\prime} \mathrm{W}$, latitude de $18^{\circ} 41^{\prime} \mathrm{S}$ e altitude de $\left.620,60 \mathrm{~m}\right)$, no ano agrícola de 2002/2003, em solo preparado com aração e gradagem apresentando as seguintes características: textura argilosa; $\mathrm{pH}$ (água) = 5,89; matéria orgânica $=2,79$ dag $\mathrm{kg}^{-1} ; \mathrm{P}=$ $9,1 \mathrm{mg} \mathrm{dm}^{-3}$; P-rem $=26,6 ; \mathrm{K}=88 \mathrm{mg} \mathrm{dm}^{-3}$; $\mathrm{Ca}^{2+}=3,72 \mathrm{cmol}_{\mathrm{c}} \mathrm{dm}^{-3} ; \mathrm{Mg}^{2+}=0,72 \mathrm{cmol}_{\mathrm{c}} \mathrm{dm}^{-3} ;$ $\mathrm{Al}^{3+}=0,0 \mathrm{cmol}_{\mathrm{c}} \mathrm{dm}^{-3} ; \mathrm{H}+\mathrm{Al}=4,8 \mathrm{cmol}_{\mathrm{c}} \mathrm{dm}^{-3}$; $\mathrm{V}=49,4 \%$; e $\mathrm{T}=9,79 \mathrm{cmol}_{\mathrm{c}} \mathrm{dm}^{-3}$.

Um dia antes da semeadura do cultivar Fabrika, realizada em 21.11.2002, fez-se a dessecação das plantas daninhas com 1,5 kg e.a. ha-1 de ghyphosate.

A adubação de plantio constou de $285 \mathrm{~kg} \mathrm{ha}^{-1}$ da fórmula 04-30-16 de NPK. A primeira adubação de cobertura, com $22 \mathrm{~kg} \mathrm{ha}^{-1}$ de $\mathrm{N}$ e $13 \mathrm{~kg} \mathrm{ha}^{-1} \mathrm{de}_{2} \mathrm{O}$, foi realizada aos 30 dias após a emergência da cultura (DAE), e a segunda, com $10 \mathrm{~kg} \mathrm{ha}^{-1}$ de $\mathrm{N}$, aos 45 DAE.

Utilizou-se o esquema fatorial $(4 \times 4)+1$, sob delineamento em blocos casualizados, com quatro repetições, em que foram avaliadas quatro doses de S-metolachlor (0, 384, 768 e $\left.1.152 \mathrm{~g} \mathrm{ha}^{-1}\right)$, quatro doses de trifloxysulfuronsodium $\left(0,0 ; 2,625 ; 5,250 ;\right.$ e $\left.7,875 \mathrm{~g} \mathrm{ha}^{-1}\right)$ e um tratamento adicional, mantido no limpo por todo o ciclo do algodoeiro. Em todas as doses do trifloxysulfuron-sodium foi adicionado Agral a 0,2\% v/v. Cada parcela possuía área de 41,65 $\mathrm{m}^{2}$ (sete linhas espaçadas de $0,85 \mathrm{~m}$, com $7 \mathrm{~m}$ de comprimento), sendo a área útil de $20,4 \mathrm{~m}^{2}$ (quatro linhas com $6 \mathrm{~m}$ de comprimento).

Após a semeadura a área foi irrigada e, no dia seguinte, aplicou-se o S-metolachlor, sob temperatura de $27^{\circ} \mathrm{C}$ e umidade relativa de $71 \%$. A emergência da cultura ocorreu cinco dias após a semeadura, e 15 dias após a emergência (DAE) das plantas de algodão foi realizado o desbaste, deixando-se oito plantas por metro linear.

O herbicida trifloxysulfuron-sodium foi aplicado aos $18 \mathrm{DAE}$ em pós-emergência total, estando o solo úmido, com temperatura de $28{ }^{\circ} \mathrm{C}$ e umidade relativa de $72 \%$; o algodoeiro apresentava quatro a cinco folhas desenvolvidas, e as plantas daninhas, até seis folhas.
Na aplicação dos herbicidas utilizou-se um pulverizador costal pressurizado a $\mathrm{CO}_{2}$, com

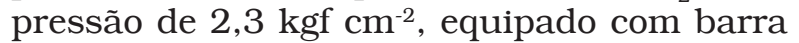
de dois bicos TT11002 espaçados de $1 \mathrm{~m} \mathrm{e}$ altura de trabalho de $0,5 \mathrm{~m}$, calibrado para aplicar $100 \mathrm{~L} \mathrm{ha}^{-1}$ de calda.

O controle das pragas foi realizado em função da necessidade, verificada por constante monitoramento da lavoura. Com o objetivo de evitar o crescimento excessivo do algodoeiro, foram feitas duas aplicações de $15 \mathrm{~g} \mathrm{ha}^{-1}$ do regulador de crescimento cloreto de mepiquat.

O controle de plantas daninhas na testemunha capinada foi feito roçando-as superficialmente, na entrelinha, sem revolvimento do solo; na linha, fez-se o arranque manual, a cada quinze dias, mantendo essas parcelas no limpo até a colheita. Aos $80 \mathrm{DAE}$ fez-se uma capina em área total do experimento, devido à reinfestação e ao rápido crescimento de Cenchus echinatus e Alternanthera tenella.

Aos 25 e 60 DAE, foram determinados o número e a matéria seca de plantas daninhas, por meio de duas amostragens de $0,25 \mathrm{~m}^{2}$ por parcela, sendo as plantas cortadas, separadas por espécie e acondicionadas em sacos de papel para posterior secagem em estufa de circulação forçada de ar, a $70 \pm 2{ }^{\circ} \mathrm{C}$, para determinação da matéria seca por espécie. Aos $45 \mathrm{DAE}$ fez-se uma avaliação visual de controle do total de plantas daninhas, atribuindo-se notas que variaram de 0 a $100 \%$, sendo 0 para ausência de controle e 100 para controle total.

Na colheita, aos 140 DAE, foram avaliados: altura de plantas, número de ramos frutíferos, número de capulhos e produtividade de algodão em caroço. A altura de plantas, o número de ramos frutíferos e o número de capulhos foram determinados em 10 plantas da área útil de cada parcela. A produtividade foi calculada colhendo-se uma área de $17 \mathrm{~m}^{2}$ (cinco metros de comprimento das quatro fileiras centrais).

Para número e matéria seca de plantas daninhas, fez-se análise descritiva dos resultados a partir da média e do desvio-padrão, enquanto para as demais características avaliadas optou-se pelo desdobramento da interação, e os modelos foram escolhidos com base na significância dos coeficientes de regressão, utilizando-se o teste $t$ em nivel de 
significância de 5\% de probabilidade, no coeficiente de determinação $\mathrm{r}^{2}=$ SQReg./SQTrat. e no significado biológico. A testemunha mantida no limpo foi comparada com os demais tratamentos pelo teste de Dunnett a 5\% de probabilidade.

\section{RESULTADOS E DISCUSSÃO}

A principal espécie daninha presente na área experimental foi Alternanthera tenella (apaga-fogo), com densidade de 176,5 \pm 42,8 plantas $\mathrm{m}^{-2}$ e matéria seca de $25,8 \pm$ $4,9 \mathrm{~g} \mathrm{~m}^{-2}$, representando, aproximadamente, $80 \%$ do total de plantas daninhas da área (Tabela 2). As demais plantas daninhas, em razão da distribuição desuniforme, foram agrupadas em dicotiledôneas (DICO) [Tridax procumbens (erva-de-touro), Bidens sp. (picãopreto), Acanthospermum hispidum (carrapichode-carneiro)] e poáceas [Cenchus echinatus (capim-carrapicho), Digitaria horizontalis (capim-colchão) e Eleusine indica (capim-péde-galinha)] (Tabela 1).

Aos 25 DAE do algodoeiro, mesmo sob a maior dose utilizada (1.152 $\mathrm{g} \mathrm{ha}^{-1}$ ), o S-metolachlor apresentou baixo desempenho no controle das plantas daninhas, embora tenha reduzido o número e a matéria seca destas. Nessa avaliação também se observou efeito do trifloxysulfuron-sodium nas plantas daninhas, com redução do número e da matéria seca destas, mesmo sendo ela realizada apenas sete dias após sua aplicação (Tabela 1). Já aos 40 DAE, apenas a matéria seca das plantas daninhas foi consideravelmente reduzida quando foram utilizados 768 e $1.152 \mathrm{~g} \mathrm{ha}^{-1} \mathrm{de}$ S-metolachlor (Tabela 2).

Houve efeito de doses dos herbicidas S-metolachlor e trifloxysulfuron-sodium no controle de plantas daninhas, sendo a interação significativa para o controle aos $45 \mathrm{DAE}$.

A maior dose de S-metolachlor proporcionou controle de apenas $40 \%$, ao passo que essa mesma dose, em plantio convencional (mesma época e infestação similar), apresentou controle superior a 90\% (Ferreira et al., 2004). Menor eficiência de S-metolachlor também foi verificada por Ferri \& Vidal (2003) em sistema de plantio direto, sendo a menor eficácia desse herbicida, neste sistema, atribuída à sua possível adsorção pela palha. Guando o trifloxysulfuron-sodium foi aplicado isoladamente, o melhor nível de controle (80\%) foi obtido com a dose de 7,875 $\mathrm{g} \mathrm{ha}^{-1}$ (Figura 1). O trifloxysulfuron-sodium nas doses de $2,625 \mathrm{~g} \mathrm{ha}^{-1} \mathrm{e} 5,250 \mathrm{~g} \mathrm{ha}^{-1}$ apresentou melhor desempenho quando combinado com S-metolachlor, verificaram-se melhores desepenhos em função do controle exercido por este último no primeiro fluxo de emergência das plantas daninhas, estando estas, no momento da aplicação do trifloxysulfuron-sodium, menos desenvolvidas, resultando em maior eficiência. Aos 45 DAE, a combinação das doses de S-metolachlor a 384, 768 e $1.152 \mathrm{~g} \mathrm{ha}^{-1}$ com $6,0 \mathrm{~g} \mathrm{ha}^{-1}$ de trifloxysulfuron-sodium proporcionou controle superior a $85 \%$, muito próximo do nível de controle (90\%) obtido com $1.152 \mathrm{~g} \mathrm{ha}^{-1}$ de S-metolachlor em pré-emergência mais $7,875 \mathrm{~g} \mathrm{ha}^{-1}$ de trifloxysulfuron-sodium aplicado em pós-emergência (Figura 1), indicando boa eficiência do trifloxysulfuron-sodium em dose menor que a usualmente recomendada. Todavia, aos $60 \mathrm{DAE}$, apenas o tratamento com $1.152 \mathrm{~g} \mathrm{ha}^{-1} \mathrm{de}$ S-metolachlor e 7,875 $\mathrm{g} \mathrm{ha}^{-1} \mathrm{de}$ trifloxysufuron-sodium apresentou nível de controle superior a $90 \%$ para A. tennella, com densidade de 14,5 \pm 9,1 plantas por $\mathrm{m}^{2} \mathrm{e}$ matéria seca de 18,2 $\pm 12,4$, e satisfatório para o total de plantas daninhas. Já a espécie C. benghalensis não foi controlada por nenhuma das combnações de herbicida (Tabela 2). Excelente controle das espécies agrupadas como outras dicotiledôneas (DICO) foi obtido, mesmo sob as menores doses de trifloxysulfuron-sodium (Tabela 2); assim, dependendo do tipo de infestação, esse herbicida poderá ser utilizado em menores doses que a recomendada $\left(7,787 \mathrm{~g} \mathrm{ha}^{-1}\right)$. Contudo, nenhuma dessas combinações foi suficiente para manter a cultura sem interfrência de plantas daninhas na colheita, havedo necessidade de roçá-las aos 80 DAE da cultura. Resultados promissores também foram encontrados por Oliveira Júnior et al. (2002) com trifloxysulfuron-sodium nas doses de 5,0; 6,3; e 7,5 $\mathrm{g} \mathrm{ha}^{-1}$, o qual foi seletivo para cultura do algodão e proporcionou controle equivalente ao pyrithiobac-sodium na dose de $140 \mathrm{~g} \mathrm{ha}^{-1}$ para as seguintes espécies daninhas: Amaranthus viridis, Raphanus raphanistrume Xanthium strumarium. Nos trabalhos desenvolvidos por Bloodworh et al. (2000), Porterfield et al. (2000) e Wilcut (2000), o trifloxysulfuron-sodim a 5,0 $\mathrm{g} \mathrm{ha}^{-1}$ apresentou controle de amplo espectro de planta daninha. 

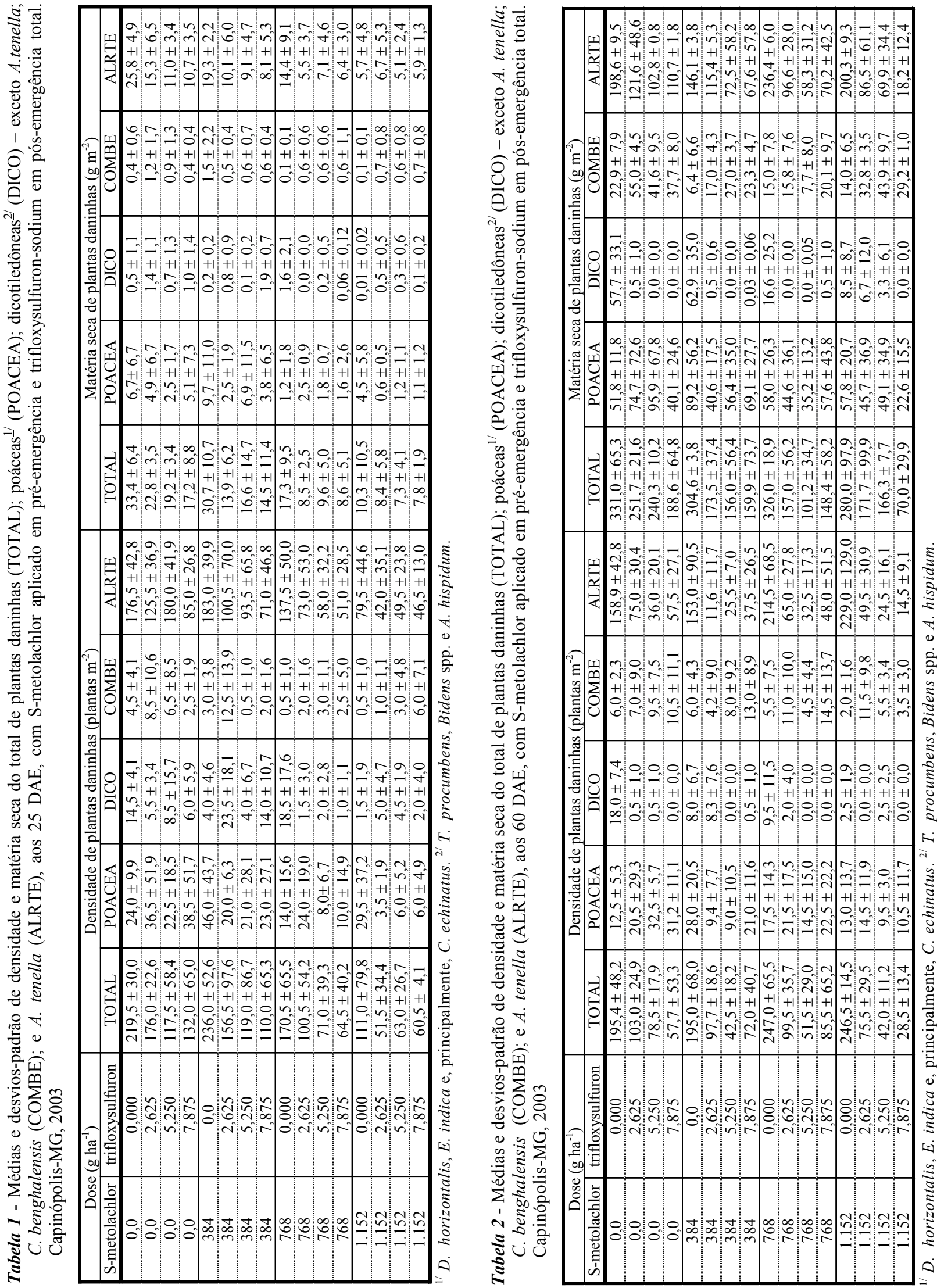

Planta Daninha, Viçosa-MG, v. 24, n. 2, p. 339-346, 2006 


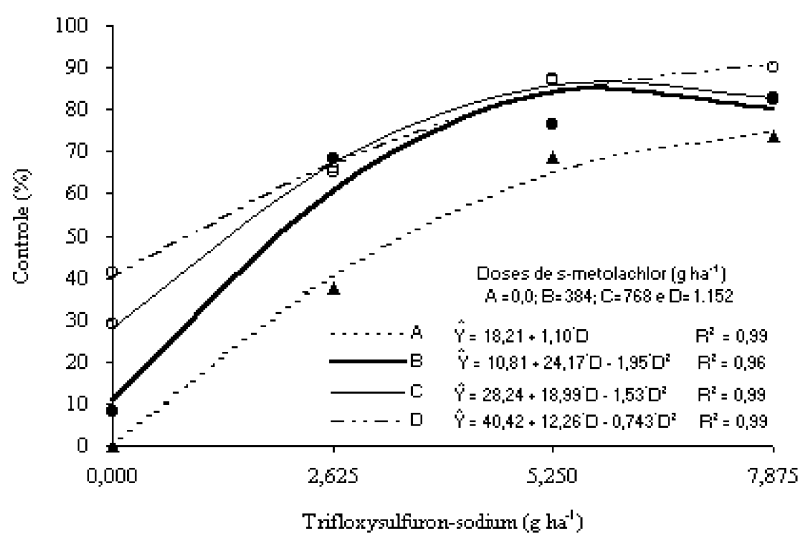

Figura 1 - Porcentagem de controle do total de plantas daninhas aos 45 DAE (27 dias após a aplicação do trifloxysulfuronsodim) em cada nível de s-metolachlor aplicado em pré-emergência, em função dos níveis de trifloxysulfuronsodium aplicado em pós-emergência.

Verificou-se que houve efeito de doses dos herbicidas S-metolachlor e trifloxysulfuronsodium para número de capulhos, altura de plantas, número de ramos frutíferos e produtividade de algodão em caroço; a interação entre as doses dos herbicidas mostrou-se significativa, proporcionando aumento na produtividade de algodão em caroço.

O trifloxysulfuron-sodium causou leve amarelecimento das plantas de algodão aos sete dias após a aplicação, porém esses sintomas não foram constatados em inspeção de campo aos 30 DAA. Já o número de capulhos por planta foi menor quando a aplicação do trifloxysulfuron-sodium não foi precedida daquela do S-metolachlor (Figura 2A, Tabela 3). $\mathrm{O}$ número de ramos e a altura de plantas mostraram comportamento similar ao da testemunha mantida no limpo quando foram utilizados 5,25 ou $7,787 \mathrm{~g} \mathrm{ha}^{-1}$ de trifloxysulfuronsodium com 384, 768 e $1.152 \mathrm{~g} \mathrm{ha}^{-1} \mathrm{de}$ S-metolachlor (Tabela 3).

A produtividade de algodão em caroço, quando o algodoeiro foi mantido no limpo por todo o ciclo, foi de $1971,6 \mathrm{~kg} \mathrm{ha}^{-1}$, muito abaixo da média nacional $\left(3120,0 \mathrm{~kg} \mathrm{ha}^{-1}\right)$ na safra de 2002/2003 (Anuário..., 2005) e da obtida no plantio convencional $\left(2816,1 \mathrm{~kg} \mathrm{ha}^{-1}\right)$. Um dos fatores que contribuíram para a baixa produtividade de algodão foi o inadequado desenvolvimento do sistema radicular, que não conseguiu penetrar adequadamente no solo, provavelmente devido a um impedimento físico. Outro fator que contribuiu para a baixa produção foi o surgimento do bicudo no início do ciclo do algodoeiro, por causa da inadequada eliminação da soqueira em propriedades adjacentes, aliado à dificuldade do controle dessa praga, principalmente nas parcelas infestadas pelas plantas daninhas.
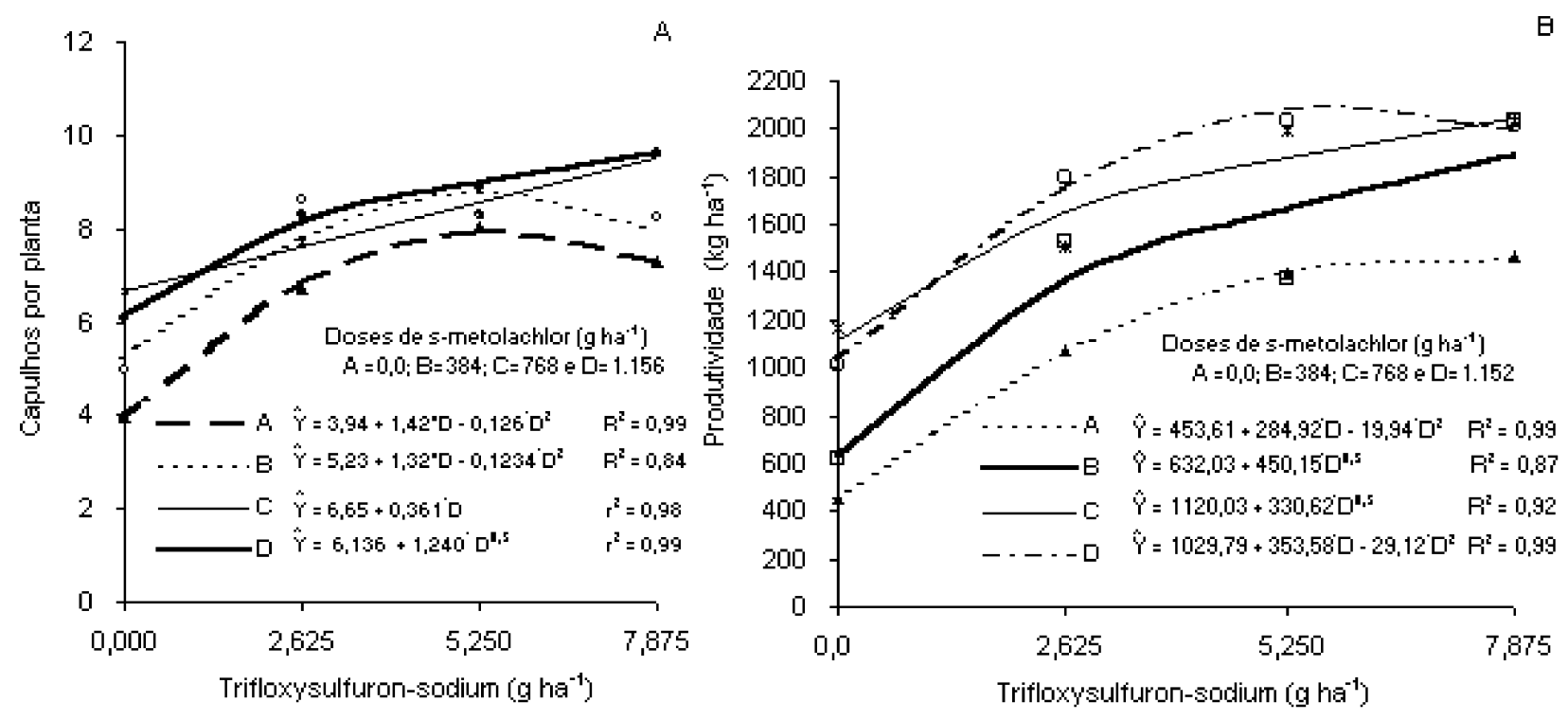

Figura 2 - Número de capulhos (A) e produtividade de algodão em caroço (B) em cada nível de S-metolachlor aplicado em pré-emergência, em função dos níveis de trifloxysulfuron-sodium aplicado em pós-emergência. 
Tabela 3 - Número de ramos, altura de plantas, número de capulhos e produtividade de algodão em caroço, em função do manejo de plantas daninhas com S-metolachlor aplicado em pré-emergência combinado com trifloxysulfuron-sodium aplicado aos 18 DAE. Capinópolis-MG, 2003

\begin{tabular}{|c|c|c|c|c|c|}
\hline \multicolumn{2}{|c|}{ Dose $\left(\mathrm{g} \mathrm{ha}^{-1}\right)$} & \multirow{2}{*}{ № . ramos/planta } & \multirow{2}{*}{ Altura $(\mathrm{cm})$} & \multirow{2}{*}{$\begin{array}{l}\mathrm{N}^{\mathrm{o}} \text {. de capulhos/ } \\
\text { planta }\end{array}$} & \multirow{2}{*}{$\begin{array}{l}\text { Produtividade } \\
\left(\mathrm{kg} \mathrm{ha}^{-1}\right)\end{array}$} \\
\hline S-metolachlor & Trifloxysulfuron & & & & \\
\hline 0,0 & 0,000 & $5,33 *$ & $76,75^{*}$ & $3,97 *$ & $450,94^{*}$ \\
\hline 0,0 & 2,625 & $7,30 *$ & $77,32 *$ & $6,70 *$ & $1.071,56^{*}$ \\
\hline 0,0 & 5,250 & $8,30^{\mathrm{ns}}$ & $88,7 *$ & $8,02^{\mathrm{ns}}$ & $1.392,20^{*}$ \\
\hline 0,0 & 7,875 & $8,66^{\mathrm{ns}}$ & $92,7^{\mathrm{ns}}$ & $7,27 *$ & $1.463,25^{*}$ \\
\hline 384 & 0,000 & $5,77 *$ & $77,47 *$ & $4,97 *$ & $625,50 *$ \\
\hline 384 & 2,625 & $9,30^{\mathrm{ns}}$ & $89,10^{*}$ & $8,55^{\text {ns }}$ & $1.525,35 *$ \\
\hline 384 & 5,250 & $8,97^{\mathrm{ns}}$ & $94,7^{\text {ns }}$ & $8,00^{\mathrm{ns}}$ & $1.371,00^{*}$ \\
\hline 384 & 7,875 & $8,52^{\mathrm{ns}}$ & $95,9^{\text {ns }}$ & $7,85^{\mathrm{ns}}$ & $2.038,20^{\mathrm{ns}}$ \\
\hline 768 & 0,000 & $7,22 *$ & $86,82 *$ & $6,65 *$ & $1.162,65^{*}$ \\
\hline 768 & 2,625 & $8,72^{\text {ns }}$ & $99,2^{\mathrm{ns}}$ & $7,72 *$ & $1.503,56^{*}$ \\
\hline 768 & 5,250 & $10,20^{\mathrm{ns}}$ & $103,0^{\mathrm{ns}}$ & $8,30^{\mathrm{ns}}$ & $1.997,70^{\text {ns }}$ \\
\hline 768 & 7,875 & $10,57^{\mathrm{ns}}$ & $97,7^{\mathrm{ns}}$ & $9,62^{\text {ns }}$ & $2.038,2^{\mathrm{ns}}$ \\
\hline 1.152 & 0,000 & $7,20^{*}$ & $85,45^{*}$ & $6,10^{*}$ & $1.009,95^{*}$ \\
\hline 1.152 & 2,625 & $8,92^{\mathrm{ns}}$ & $100,1^{\mathrm{ns}}$ & $8,27^{\mathrm{ns}}$ & $1.792,84^{*}$ \\
\hline 1.152 & 5,250 & $9,40^{\mathrm{ns}}$ & $96,7^{\text {ns }}$ & $8,87^{\mathrm{ns}}$ & $2.036,02^{\mathrm{ns}}$ \\
\hline 1.152 & 7,875 & $10,20^{\mathrm{ns}}$ & $97,50^{\mathrm{ns}}$ & $9,6^{\mathrm{ns}}$ & $2.016,30^{\mathrm{ns}}$ \\
\hline Test. capinada & --- & 9,80 & 99,15 & 9,02 & $1.971,60$ \\
\hline $\mathrm{CV}(\%)$ & -- & 13,78 & 9,43 & 15,33 & 11,28 \\
\hline
\end{tabular}

* Significativo e ${ }^{\text {ns }}$ não-significativo pelo teste de Dunnett a 5\% de probabilidade (comparado com a test. capinada).

A produtividade de algodão em caroço foi maior quando se utilizou trifloxysulfuronsodium após a aplicação de S-metolachlor e aumentou com o incremento da dose dos herbicidas (Figura 2B). A produtividade de algodão foi semelhante à da testemunha mantida no limpo nas seguintes combinações dos herbicidas: $384 \mathrm{~g} \mathrm{ha}^{-1}$ de S-metolachlor com $7,875 \mathrm{~g} \mathrm{ha}^{-1}$ de trifloxysulfuron; $768 \mathrm{e}$ $1.152 \mathrm{~g} \mathrm{ha}^{-1}$ de S-metolachlor com 5,25 ou $7,875 \mathrm{~g} \mathrm{ha}^{-1}$ de trifloxysulfuron-sodium (Tabela 3). Esses tratamentos evitaram a interferência das plantas daninhas no algodoeiro durante o período crítico de prevenção da interferência, que, segundo Salgado et al. (2002), pode-se estender até 66 dias da emergência da cultura.

Desse modo, conclui-se que o melhor controle de plantas daninhas foi obtido com a combinação de S-metolachlor a $1.152 \mathrm{~g} \mathrm{ha}^{-1}$ com trifloxysulfuron-sodium a $7,787 \mathrm{~g} \mathrm{ha}^{-1}$, visto ter ela apresentado controle superior a 90\% de A. tenella e do total de plantas daninhas até 60 DAE e produtividade semelhante à da testemunha mantida no limpo, embora nenhuma das combinações herbicidas tenha permitido a colheita de algodão sem interferência das plantas daninhas. O trifloxysulfuronsodium tem potencial para ser utilizado em dose menor que a comumente recomendada $\left(7,5 \mathrm{~g} \mathrm{ha}^{-1}\right)$ pelo fabricante. O S-metolachlor apresentou reduzido desempenho no controle das plantas daninhas sob sistema de semeadura direta.

\section{LITERATURA CITADA}

ANUÁRIO DA AGRICULTURA BRASILEIRA. Algodão. In: Agrianual 2005. São Paulo: Argos, 2005. p. 181-198.

BANKS, A. P.; ROBINSON, E. L. Soil reception and activity of acetochlor, alachlor, and metolachlor as affected by wheat (Triticum aestivum) straw and irrigation. Weed Sci., v. 34, n. 3, p. 607-611, 1986.

BELTRÃO, N. E. M. Manejo e controle de plantas daninhas em algodão. In: VARGAS, L.; ROMAN, E. S. (Eds.). Manual de manejo e controle de plantas daninhas. Bento Gonçalves: Embrapa Uva e Vinho, 2004. p. 215-250.

BLOODWORTH, K. M. et al. Cotton weed control in Mississipi with CGA-362622. In: SOUTHERN WEED SCIENCE SOCIETY, 54., 2000, Atlanta. Proceedings... Atlanta: Hyatt Regency, 2000. p. 28. 
BURGOS, N. R.; TALBERT, R. E. Weed control and sweet corn (Zea mays var. rugosa) response in a no-till system with cover crops. Weed Sci., v. 44, n. 2, p. 355-361, 1996.

CROOKS, H. L.; YORK, A. C.; CULPEPPER, A. S. Interactions of CGA 362622 and graminicides on annual grasses in cotton. Weed Sci. Soc. Am. Abstr., v. 41, p. 59, 2001.

FERREIRA, L. R.; FREITAS, R. S. BERGER. P. G. Manejo de plantas daninhas na cultura do algodoeiro. In: CONGRESSO BRASILEIRO DA CIÊNCIA DAS PLANTAS DANINHAS, 24., 2004, São Pedro-SP. Anais ... São Pedro: Sociedade Brasileira da Ciência das Plantas Daninhas, 2004. p. 175. CD ROM.

FERRI, M. V. W.; VIDAL, R. A. Controle de plantas daninhas na cultura da soja através do herbicida acetolachlor em sistemas de semeadura direta e preparo convencional. Planta Daninha, v. 20, n. 2, p. 283-290, 2002.

FERRI, M. V. W.; VIDAL, R. A. Controle de plantas daninhas com herbicidas cloroacetamidas em sistemas de plantio convencional e de semeadura direta. Planta Daninha, v. 21, n. 1, p. 131-136, 2003.

FOLONI, L. L.; RODRIGUES, J. D.; ONO, E. O. Avaliação de tratamentos químicos e mecânicos no controle de plantas daninhas na cultura do algodão. Planta Daninha, v. 17, n. 1, p. 5-20, 1999.

FREITAS, R. S. et al. Interferência de plantas daninhas na cultura do algodão em sistema de plantio direto. Planta Daninha, v. 20, n. 2, p. 197-205, 2002.

FREITAS, R. S. Interferência de plantas daninhas na cultura do algodão. R. Ceres, v. 44, n. 256, p. 597-603, 2003.

GUTHRIE, D. S.; YORK, A. C. Cotton (Gossypium hirsutum) development and yield following fluometuron postermergence applied. Weed Technol., v. 3, p. 501-504, 1989.

HEWSON, R. T.; ROBERTS, H. A. Effects of weed competition for different periods of growth on yield of red beet. J. Hortic. Sci., n. 48, p. 281-292, 1973.

HOLLOWAY Jr., W. et al. CGA-362622 aplication timing, rates, and weed spectrum in cotton. In: SOUTHERN WEED SCIENCE SOCIETY, 53., 2000, Atlanta. Proceedings ... Atlanta: Hyatt Regency, 2000. p. 140-141.

HUDETZ, M. CGA 362622, a new low rate Novartis postemergent herbicide for cotton and sugarcane. In: SOUTHERN WEED SCIENCE SOCIETY, 53., 2000, Atlanta. Proceedings ... Atlanta: Hyatt Regency, 2000. p. 163-166.

LACA-BUENDIA, J. P. Controle das plantas daninhas na cultura algodoeira. Inf. Agropec., v. 8, n. 92, p. 37-47, 1990 .

Planta Daninha, Viçosa-MG, v. 24, n. 2, p. 339-346, 2006
MONKS, C. D. Effect of pyrithiobac, MSMA, and DSMA on cotton (Gossypium hirsutum L.) growth and weed control. Weed Technol., v. 13, p. 6-11, 1999.

NIETO, G.; BRONDO, M. A.; GONZALEZ, J. T. Critical periods of the crop growth cycle for competition from weeds. Pans, v. 2, n. 14, p. 159-166, 1968.

O’CONNELL, P. J.; HARMS, C. T.; ALLEN, J. R. F. Metolachlor, S-metolachlor and their role within sustainable weed-management. Crop Protec., v. 17, p. 207-212, 1998.

OLIVEIRA JÚNIOR, R. S. O. Avaliação da eficácia do herbicida trifloxysulfuron-sodium para o controle de ervas de folhas largas em pós-emergência na cultura do algodoeiro. In: CONGRESSO BRASILEIRO DE PLANTAS DANINHAS, 23., 2002, Gramado. Resumos ... GramadoRS: Sociedade Brasileira da Ciência das Plantas Daninhas, 2002. p. 479.

PITELLI, L. A. Interferência de plantas daninhas em culturas agrícolas. Inf. Agropec., v. 11, n. 129, p. 16-27, 1985.

PORTERFIELD, D.; WILCUT J. W.; ASKEW, S. D. Weed management with CGA-362622, fluometuron, and prometryn in cotton. Weed Sci., v. 50, n. 5, p. 642-647, 2002.

PORTERFIELD, D. Weed-free yield response of seven cotton (Gossypium hirsutum) cultivars to CGA-362622 postemergence. Weed Technol., v. 16, p. 180-183, 2002.

PROCÓPIO. S. O. et al. Seleção de plantas com potencial para fitorremediação de solos contaminados com o herbicida trifloxysulfuron-sodium. Planta Daninha, v. 22, n. 2, p. 315-322, 2004.

RODRIGUES, A. M.; ALMEIDA, F. S. Guia de herbicidas. 5.ed. Londrina: Edição dos Autores, 2005. 592 p.

SALGADO, T. P. et al. Períodos de interferência das plantas daninhas na cultura do algodoeiro (Gossypium hirsutum).

Planta Daninha, v. 20, n. 3, p. 373-379, 2002.

SNIPES, C. E.; MUELER, T. C. Influence of fluometuron and MSMA on cotton yield and fruiting characteristics. Weed Sci., v. 42, p. 210-215, 1992.

TAKIZAWA, E. K. Manejo de plantas daninhas na cultura do algodão. In: CONGRESSO INTERNACIONAL DO AGRONEGÓCIO DO ALGODÃO; SEMINÁRIO ESTADUAL DA CULTURA DO ALGODÃO, 5., 2000, Cuiabá. Anais ... Cuiabá: Fundação MT, 2000. p. 147-152.

TROXLER, S. T. Weed management in transgenic and nontransgenic Gossypium hirsutum with CGA-362622, pyrithiobac, bromoxynil, and ghyphosate. Weed Sci. Soc. Am. Abstr., v. 41, p. 58, 2001.

WILCUT, S. S.; ASKEW, S. D.; PORTERFIELD, D. Weed management in non-transgenic and transgenic cotton with CGA 362622. In: SOUTHERN WEED SCIENCE SOCIETY, 53., 2000, Atlanta. Proceedings ... Atlanta: Hyatt Regency, 2000. p. 27. 